DEFINING ACCESSIBILITY:

\title{
A SNAPSHOT OF ACCESSIBILITY PLANNING AND A REVIEW OF PRACTICE IN ONTARIO
}

\author{
by \\ Ashley E. Varajão \\ Honours Bachelor of Arts, University of Toronto, 2014 \\ A Major Research Paper \\ presented to Ryerson University \\ in partial fulfillment of the requirements for the degree of \\ Master of Planning \\ in the Program of \\ Urban Development
}

Toronto, Ontario, Canada, 2017

(C) Ashley E. Varajão 2017 


\section{AUTHOR'S DECLARATION}

I hereby declare that I am the sole author of this MRP. This is a true copy of the MRP, including any required final revisions.

I authorize Ryerson University to lend this MRP to other institutions or individuals for the purpose of scholarly research.

I further authorize Ryerson University to reproduce this MRP by photocopying or by other means, in total or in part, at the request of other institutions or individuals for the purpose of scholarly research.

I understand that my MRP may be made electronically available to the public. 


\title{
ABSTRACT \\ DEFINING ACCESSIBILITY: A SNAPSHOT OF ACCESSIBILITY PLANNING AND A REVIEW OF PRACTICE IN ONTARIO
}

\author{
Master of Planning 2017 \\ Ashley E. Varajão \\ Urban Development \\ Ryerson University
}

Despite the growing importance of accessibility planning and the legislated recognition of Human Rights in the planning profession, there is no universal, operational definition of accessibility planning. Moreover, the objectives of accessibility planning for municipalities and the private sector are largely ambiguous beyond the point of minimum Ontario Building Code standards. This MRP provides an annotated bibliography on the various subcategories that inform accessibility planning, which can act as a starting point for practitioners who are unfamiliar with the subject. The paper also analyzes the current understanding of accessibility in planning and related fields to provide an immediate understanding of accessibility, as well as note areas of similarity or conflict in varying sectors. The report concludes with a discussion of some potential areas for future research and development within the field. 


\section{ACKNOWLEDGEMENTS}

Thank you to the graduate programs that sent me rejection letters, who forced me to take a year

off and introduce myself to a world outside of academics. That experience inevitably shaped the choices I would go on to make in pursuing a Master of Planning.

A very important thank you goes to my Portuguese comrade and supervisor, Chris de Sousa. I appreciate your taking a step back, allowing me to explore my passions, and making thoughtful suggestions when needed.

Raymond Ziemba, I blame you for showing me doors I would not have otherwise opened, encouraging me to do work I would have rather skipped. Thank you for gently pushing me, always. 


\section{TABLE OF CONTENTS}

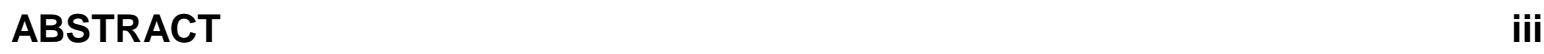

LIST OF TABLES vi vi

CHAPTER 1: Introduction 1

CHAPTER 2: Methods $\quad 3$

CHAPTER 3: Annotated Bibliography $\quad 5$

3.1: Policy and Design Standards $\quad 5$

3.2: Additional Policy and Design Standards $\quad 7$

3.3: Universal Design and Other Design Principles 9

3.4: DeafSpace 13

3.5: Age Friendly Communities and Dementia-Friendly Design 15

3.5.1: Age Friendly Communities $\quad 17$

3.5.2: Dementia-Friendly Design 19

3.6: Visual Impairment $\quad 20$

3.7: Mobility

$\begin{array}{ll}\text { CHAPTER 4: Results and Discussion } & 27\end{array}$

4.1: Defining Accessibility 28

4.2: Successful Projects $\quad 29$

4.3: Harmonized Standards and Outcomes $\quad 30$

4.4: Barriers 31

4.4.1: Funding 32

4.4.2: Monitoring and Enforcement 33

4.4.3: Education and Perceptions $\quad 34$

CHAPTER 5: Next Steps and Conclusion $\quad 35$

$\begin{array}{ll}\text { REFERENCES } & 37\end{array}$

$\begin{array}{ll}\text { GLOSSARY } & 41\end{array}$ 


\section{LIST OF TABLES}

Table 1: The difference between the Accessibility for Ontarians with Disabilities

Act (2005) and the Ontarians with Disabilities Act (2001) 


\section{CHAPTER 1: INTRODUCTION}

Cities have traditionally developed with a particular vision of its user: an individual who is a young adult, physically able, who has control of their mobility choices, and is largely capable of using their environments to meet their needs and desires. The safety and dignity of individuals who may have different abilities when compared to the majority is diminished due to the prioritizing of certain societal values. Where planners and designers have erred is their assumption that in complex urban systems there is only one user type. Many statistics can help establish the growing number of individuals who do not fit into the described mold above. In Canada, $13.7 \%$ of adults live with a disability and $33.2 \%$ of seniors aged 65 or older reported that they have a disability (Statistics Canada, 2012). However, this paper will make a concerted effort to avoid the term disability to further contribute to the dialogue surrounding ability. Communities are made up of individuals who embody a range of abilities that are affected by mobility constraints, visual impairment, reduced hearing, cognitive ability, and age (young and old), which can be biologically determined or due to external trauma. Accessibility does not necessarily target one type of individual who is seen as disabled, rather it provides undifferentiated user experiences, allows for independence, and most importantly provides a sense of dignity that all citizens are entitled too.

Individuals are protected under both the Canadian Charter of Rights and Freedoms, and Ontario's Human Rights Code. Accessibility considerations have begun transitioning from an afterthought to a required priority. Despite the growing importance of accessibility planning and the legislated recognition of Human Rights in the profession, planners have been slow in their uptake. Arguably, this is due in part to a lack of commonly shared values towards accessibility as there is no harmonized, operational definition of accessibility planning. Moreover, the objectives of accessibility planning for municipalities and the private sector are largely ambiguous beyond the point of minimum Ontario Building Code (OBC) standards. OBC Standards, in and of themselves, are mainly limited to the provision of barrier-free entrances, paths, washrooms, and parking. The Accessibility for Ontarians with Disabilities Act (AODA) recognizes a broader understanding of ability and seeks to create an inclusive society where everyone can fully participate within a range of abilities. This report has two goals to present:

1. A summarized, annotated bibliography on the various subcategories that inform accessibility planning, which can act as a starting point for practitioners who are unfamiliar with the subject; and 
2. Analyze the current understanding of accessibility in planning and related fields to provide an immediate understanding of accessibility, as well as note areas of similarity or conflict in varying sectors. 


\section{CHAPTER 2: METHODS}

The methodology of this project consisted first with the amassing of an extensive, contemporary literature review, which includes academic, policy, and best practice research. This informed the development of an annotated bibliography which is classified according to relevant policy, design principles, and disability specific literature.

To allow for conducting private semi-structured interviews with accessibility professionals, this research project was reviewed and approved by the Ryerson Research Ethics Board in December 2016. The interviews were held either in person or over the phone with either written or verbal consent being obtained. Notes were taken during the interview process, however no recordings were conducted.

The recruitment process consisted of cold emailing individuals based on their publically available professional biographies, which identified each individual as having a particular expertise in the field. The participants recruited were both male and female adults over eighteen years of age who have worked a minimum of five years within the above outlined fields.

Interviews were conducted with local accessibility planners and professionals in related fields consisting of architects, academics, consultants, and accessibility specialists. The recruitment sought to reach a diverse mix of professionals in the private and public sectors that are involved in creating and executing accessible design principles, universal design outcomes, and have an overall professional interest in creating accessible spaces.

It was important for this project to capture an immediate understanding of how professionals engaged in work relating to AODA compliance, barrier-free design, accessibility, and universal design were interpreting accessibility in their work. The interviews provided a more enriched understanding of some of the central themes discussed in the literature. Moreover, since accessibility is an emerging field, interviews had the potential to highlight gaps in the literature.

This report analyzes data to determine points of similarity or difference within the private and public sectors, as well as summarize key findings. The data collected from the professionals will be used to create a baseline for what accessibility planning is today, as well as a working definition. Moreover, participants were asked to identify areas of contention or improvement 
regarding the processes in place affecting accessibility outcomes.

A limitation to this methodology is the small sample size of twelve participants; it is difficult to find significant relationships, and it is not a robust representation of the population of professionals in this field. However, due to the qualitative nature of this research as well as the niche nature of accessibility planning as a profession, the interviews still are successful in capturing a range of the opinions held within the field. 


\section{CHAPTER 3: ANNOTATED BIBLIOGRAPHY}

\section{CHAPTER 3.1: POLICY AND DESIGN STANDARDS}

As briefly touched upon in the introduction, discrimination based on ability is protected by Rights and Freedoms, and Human Rights legislation. The Ontario Human Rights Code has primacy over the AODA when the laws are in conflict. However, both pieces are tools that work together in promoting equality and accessibility. Essentially, the Code outlines a duty to accommodate individuals but does not strictly apply to architecture; while the AODA outlines accessibility standards that must be met in multiple sectors, which include the built environment among other things. The OBC provides minimum standards for barrier-free design as it applies to building interiors. The following is an outline of the relevant Canadian and Ontario policy that impact accessibility and planning.

\section{Ontario Human Rights Code, 1990}

These legislations outline the essential laws and protections that grant all citizens equal rights to employment, housing, services, facilities, and various other entities, without discrimination based on race, sex, disability, age, etc.

All laws in Ontario must follow the above legislation. Moreover, the planning profession must also abide with the human rights legislation. As a result, in the context of accessibility, planners must be cognizant of professional choices that affect individuals who identify as having a disability. Particularly, the built environment and public spaces have the potential to be discriminating experiences for some individuals.

\section{Accessibility for Ontarians with Disabilities Act, 2005}

The Act was established to implement and enforce mandatory accessibility standards in achieving an inclusive Ontario by 2025 . The Act centers around five accessibility standards: customer service, transportation, information and communication, employment, and the built environment. Arguably, all five of these standards impact the planning profession in some way; however, it is the built environment that professionals have to be particularly aware of. Moreover, the Act also includes details on the Design of Public Spaces Standards (Accessibility 
Standards for the Built Environment) in Part IV.1.

Ontarians with Disabilities Act, 2001

The Ontarians with Disabilities Act (ODA) seeks "to improve the identification, removal and prevention of barriers faced by persons with disabilities and to make related amendments to other Acts," while the AODA also seeks to address accessibility issues. Both acts remain in force but the AODA has taken precedence.

A short note of the difference between the AODA and the ODA:

\begin{tabular}{|l|l|}
\hline AODA & ODA \\
\hline Seeks to promote accessibility & Seeks to improve accessibility \\
\hline 2025 timeframe & No timeframe \\
\hline Both public and private application & Public application only \\
\hline Seeks accessibility standards & Does not seek accessibility standards \\
\hline
\end{tabular}

Table 1: The difference between the Accessibility for Ontarians with Disabilities Act (2005) and the Ontarians with Disabilities Act (2001) (Regional Municipality of York, 2017)

\section{Ontario Building Code, 2012}

Section 3.8 of the OBC provides details regarding barrier-free design, however, some individuals interviewed have stated that this is not only a limited source of information, it is also sometimes in conflict with other sections of the OBC. Further, the OBC does not capture many design details that support individuals with sensory or cognitive disabilities; rather, the emphasis is placed greatly on manual wheelchair users experiences. 


\section{CHAPTER 3.2: ADDITIONAL POLICY AND DESIGN STANDARDS}

The legislation described above is of course not all encompassing. The following policies and design standards have been identified by the individuals who have participated in this research project as being key documents that they refer to on a regular basis to inform their design decisions and recommendations. The success of these documents is widely attributed to the extensive information they provide informed by best practices as well as universal design principles.

\section{Americans with Disabilities Act, 1990; Standards for Accessible Design, 2010}

The Americans with Disabilities Act and the supporting Standards for Accessible Design document are similar to the AODA. The main distinction is they provide clear regulations and enforceable accessibility standards. The Act and Standards apply for new construction and retrofitting of government facilities, public accommodations, and commercial facilities to be "readily" accessible.

\section{City of Toronto, Accessibility Design Guidelines, 2004}

Intended to be used by City staff during the development of capital projects, the guideline is broadly based on universal design principles. This is the City's effort to prepare a coherent guideline that accounts not only for mobility needs, but also sight, hearing, and/or cognitive disabilities.

\section{City of Mississauga, Facility Accessibility Design Standards, 2015}

Formerly the Mississauga Accessibility Design Handbook, the Facility Accessibility Design Standards outlines the standards for a universally designed and accessible city. The updated standard also includes requirements related to sensory disability. It applies to all new and renovated City-owned, -leased or -operated facilities.

\section{City of London, Facility Access Design Standards, 2007}

This technical design document created by the City of London is described as providing 
guidance that goes beyond the minimum requirements of the $\mathrm{OBC}$, as well as including universal design principles. Although intended for the design of municipal facilities, practitioners have described favoring this document in a wide spectrum of their work when seeking to remove and prevent barriers.

Canadian Standards Association, Accessible design for the built environment, 2012

This document provides thorough information on accessibility in the built environment. It seeks to go beyond the provincial building codes, significantly exceeding minimum standards and providing more detailed material. This document was widely used by the individuals interviewed. 


\section{CHAPTER 3.3: UNIVERSAL DESIGN AND OTHER DESIGN PRINCIPLES}

Two paths for accessibility planning have emerged, planners and designers can simply pursue creating barrier-free design for individuals who identify as having a disability, or there are those who are proponents of universal design.

Universal design emphasizes universal access for individuals of all abilities. It is sometimes colloquially referred to as 8 to 80 or 9 to 95 design, meaning it is an approach that would support the needs of individuals from 8 to 80 years of age. Universal design also aims to include more subtle design choices. For example, one would not see the international symbol for disability (the wheelchair) demarcating uses. Instead, an entire space would simply be accessible for all users.

There are other design principles such as inclusive design, accessible design, and universal access. They are all fairly interrelated and share similarities to universal design. The above noted approaches vary most significantly in the extent that the design outcome would support an individual. There is also cooperative/participatory design, which involves individuals who identify as having a disability in the design process, this approach is used in the various accessibility advisory committees across the province.

Universal design is a contentious and critiqued topic in the literature, as it often results in certain design choices conflicting with needs of different user groups (Law et al. 2007; Gossett et al., 2009). However, an in-depth exploration of the conflicts that arise due to universal design is absent from the literature. A large majority of researchers find universal design to be the most optimal plan of action for designing cities (Law et al., 2007; Weisman, 2000; Steinfeld and Maisel, 2012; City of New York, 2001). City policies and design guidelines are increasingly relying on universal design and inclusive design principles to inform their work (City of New York, 2001; City of New York, 2003; Imrie and Hall, 2001; Law et al., 2007).

\section{Law, C. M., Yi, J. S., Choi, Y. S., \& Jacko, J. A. (2007). Unresolved Problems in Accessibility and Universal Design Guidelines. Ergonomics in Design: The Quarterly of Human Factors Applications, 15(3), 7-11.}

The authors provide an interesting analysis of universal design, and outline five key issues 
including: (1) the identification of target users, (2) creation of a clear definition of accessibility, (3) development of an evaluation tool, (4) enforcement of accessibility standards, and (5) usability of design guidelines. This report is more of a practical guide for practitioners who are in the process of developing implementation strategies that include universal design principles.

Persson, H., Åhman, H., Yngling, A. A., \& Gulliksen, J. (2014). Universal Design, Inclusive Design, Accessible Design, Design for All: Different Concepts-One Goal? On the Concept of Accessibility-Historical, Methodological and Philosophical Aspects. Universal Access in the Information Society, 14(4), 505-526.

This article details the concept of universal design and the other design principles mentioned above: inclusive design, accessible design, universal access, and cooperative/participatory design. For individuals who are new to the concept of accessibility planning, the authors provide a strong introductory and educational piece.

Gossett, A., Gossett, A., Mirza, M., Barnds, A. K., \& Feidt, D. (2009). Beyond Access: A Case Study on the Intersection Between Accessibility, Sustainability, and Universal Design. Disability and Rehabilitation: Assistive Technology, 4(6), 439-450.

Individuals with disabilities are often restricted in their social participation due to physical and virtual barriers. The article explains the intent of universal design, which seeks to apply to the largest group of users. They also outline good universal design elements. The authors go into detail explaining that sometimes design choices are in conflict with different user groups, as in what is a successful design feature for someone in a wheelchair may not be ideal for someone with vision impairment. This is a crucial feature to consider in universal design and is sometimes overlooked by designers and planners.

Weisman, L. K. (2000). Creating the Universally Designed City: Prospects for the New Century. Architectural Theory Review, 5(2), 156-173.

Weisman takes a more nuanced approach to universal design and broadens it to apply to the development of cities in the future. She is not working from a traditional perspective that focuses only on disability, instead choosing to emphasize a design's influence on well-being for a variety of user groups who are stratified by age, income, race, orientation, etc. In particular, Weisman 
applies universal design to apply to "substandard housing and infrastructure, unhealthy cities and buildings, and inadequate public transit and safety".

\section{Salmi, P. (2009) Wayfinding Design: Hidden Barriers to Universal Access. Informed Design. 5(8): 1-6}

Wayfinding in its purest form is the process individuals use to navigate in unfamiliar spaces. Although everyone uses wayfinding techniques, recently, there has been a greater emphasis on creating navigable environments that support those with cognitive disabilities, seniors with memory loss, and recent immigrants. Salmi provides an introductory piece to understanding features that work for and against wayfinding.

\section{City of New York (2001) The NYC Guidebook to Accessibility and Universal Design. Retrieved from: http://www.nyc.gov/html/ddc/downloads/pdf/udny/udny2.pdf}

The City of New York through the Department of Design and Construction provides a comprehensive understanding of universal design that was referenced by many professionals who participated in this study. This guidebook is intended to be a practical reference manual that presents universal design principles in a concise and easily interpreted manner. The City as a whole is underway in their efforts to become universally accessible.

Imrie, R., \& Hall, P. (2001). Inclusive Design: Designing and Developing Accessible Environments. New York: Spon Press.

This book draws upon practices of inclusive design from the UK, Sweden, New Zealand and the USA. Imrie and Hall provide useful commentary on efforts by developers and architects to respond to the building needs of people with disabilities. The book also outlines some design practices for particularly commercial developments.

\section{Steinfeld, E., \& Maisel, J. (2012). Universal Design: Creating Inclusive Environments. Hoboken: John Wiley \& Sons, Inc.}

Described as "a much-needed reference to the latest thinking in universal design", this book is highly effective in acting as a resource for best practices in applying universal design. The book 
addresses topics such as barriers, public and private spaces, public transportation, product design, and social participation. It is a valuable resource for professionals seeking to create spaces that are accessible without the traditional or obvious design features. 


\section{CHAPTER 3.4: DEAFSPACE}

Traditionally, cities do not readily address the needs of individuals who use sign language with narrow or crowded pathways, immobile or linear seating, and visual clutter acting as barriers to the deaf community. DeafSpace is an emerging field of design and planning seeking to address these needs. The goal of DeafSpace design is to create opportunities that expand visual connections, reduce obstacles in accessing spaces, and improve social inclusion. Pioneered by Gallaudet University, Washington, DC, the premise of DeafSpace is to include particular design considerations in public and institutional spaces that allow for ample "signing space", conversational orientations, and reduce visual stimuli.

For individuals who are deaf or hard of hearing, American Sign Language or Langue des Signes Québécoise are their primary forms of communication in Canada, sign language generally requires larger spaces to increase visibility and range of motion, and allow for communication circles.

The literature on planning for reduced hearing in the built form is limited and only just being developed over the last four years, suggesting an opportunity for further research, particularly in determining the long-term outcomes of DeafSpace design. Bauman (2014) in his discussion of DeafSpace provides a very practical outline of the necessary design features. The literature also explores themes of hearing-centered design choices, which fit into the discussions of ableist city design (Harold, 2013), and the tendency for deaf people to form their own communities (Solvang and Haualand, 2013). Edwards and Harold's (2014) critique of universal design's inapplicability to deaf design resonates with similar discussions in the literature that find shortcomings in universal design outcomes (Law et al., 2007).

\section{Bauman, H. (2014). DeafSpace: A rich sensory world. Access by Design, 139, 17-25}

The sensory experiences within spaces are widely overlooked, particularly considerations for vision and touch in designing visually quiet, legible spaces. Bauman, architect and developer of DeafSpace design guidelines, provides an introduction of said principles. Reviewing concepts that are responsive to deaf ways of being, such as visual language, orientation, wayfinding or mobility. Bauman offers simple design interventions that designers can apply to both indoor and outdoor public spaces and the reasoning that informs these decisions. 
Edwards, C., \& Harold, G. (2014). DeafSpace and the principles of universal design. Disability \& Rehabilitation, 36(16), 1350-1359.

Edwards and Harold offer a widely shared critique of the universal design approach as unable to address certain nuances of individual needs. Particularly, they discuss universal design in relation to DeafSpace and the $\mathrm{d} /$ Deaf cultural identity. The authors note that DeafSpace is distinguished from universal design as it offers a more user-centered process that prioritizes addressing the impairment directly. This article unpacks the understanding of the $d /$ Deaf cultural identity and its relationship to the built environment. As well, it discusses the principles associated with DeafSpace, including space and proximity, sensory reach, mobility and proximity, light and colour, and acoustics.

Harold G. (2013) Reconsidering sound and the city: asserting the right to the Deaffriendly city. Environment and Planning D: Society and Space. 31, 846-62.

This article unpacks the "hearing-centered dispositions" that underlie design choices of public spaces and service provision. Readers begin to understand the extent of the role that sound plays in producing spaces and the resulting uninformed discrimination that regularly occurs.

Solvang, P. K., \& Haualand, H. (2013). Accessibility and diversity: Deaf space in action. Scandinavian Journal of Disability Research, 16(1), 1-13.

This article provides insights into the function of deaf communities. Deaf people do not see deafness as a disability because they have their own communities (this is a highly disputed perspective). Particularly, community groups deafen a space when they gather together and share that commonality; this is significant when designing public spaces that can facilitate the temporary deafening of space. 


\section{CHAPTER 3.5: AGE FRIENDLY COMMUNITIES AND DEMENTIA-FRIENDLY DESIGN}

On the topic of designing spaces that consider age, there are two main areas of research: age friendly communities and dementia-friendly design. Age friendly communities, particularly as defined by the World Health Organization (WHO), "encourage active ageing by optimizing opportunities for health, participation and security in order to enhance quality of life as people age" (2007). It seeks to create communities that support and extend opportunities for ageing in place.

Also related to the health of older adults is the concept of dementia-friendly design, which seeks to create safe and understandable environments for individuals with dementia and Alzheimer's disease. Design principles include cues for understanding use of space, simple patterns that minimize effects on depth perception, and legible wayfinding techniques.

On the subject of aging, the literature is expansive; various studies have been conducted to determine the appropriate means to foster active aging or aging in place, to maintain independence (Cao, Mokhtarian and Handy, 2010; Kerr, Rosenberg and Frank, 2012; Mitra, Siva and Kehler, 2015; Beard and Petitot, 2010). There is a growing body of work focusing on the physical health needs of older adults (Mitra, Siva and Kehler, 2015; Beard and Petitot, 2010). The trend in the literature appears to center at the neighbourhood level, prioritizing walkability, complete communities and transit options (Cao, Mokhtarian and Handy, 2010; Mitra, Siva and Kehler, 2015; Kerr, Rosenberg and Frank, 2012).

Unlike the extensive research on aging, the literature on dementia-friendly design is slowly emerging as the disease becomes more prevalent. The core areas of research are centered on understanding environmental stressors, design interventions, and the development of features that support wayfinding. The vast majority of studies seek to understand the experience of public space and to determine the impact on individuals with dementia (Brorsson et al., 2011; Sheehan, Burton and Mitchell, 2006; Mitchell and Burton, 2006). Generally, the literature has found that individuals are limited in their radius of comfort near their homes and experience significant levels of anxiety (Brorsson et al., 2011; Sheehan, Burton and Mitchell, 2006; Mitchell and Burton, 2006). As well, the literature on wayfinding techniques for individuals with dementia is sometimes in conflict with the literature regarding the general public. There is a greater weight placed on creating familiar, legible, and distinctive spaces to ensure safety, and less on 
directionality (Mitchell, Burton and Raman, 2004; Sheehan, Burton and Mitchell, 2006; Salmi, 2009). 


\section{CHAPTER 3.5.1: AGE-FRIENDLY COMMUNITIES}

World Health Organization (2002). Active aging: A policy framework. Retrieved from http://www.who.int/ageing/publications/active_ageing/en/

World Health Organization (2007). Global Age-Friendly Cities Guide. Retrieved from http://www.who.int/ageing/publications/Global_age_friendly_cities_Guide_English.pdf?u $a=1$

World Health Organization (2007). Checklist of Essential Features of Age-Friendly Cities. Retrieved from http://www.who.int/ageing/publications/Age_friendly_cities_checklist.pdf

The above noted documents are the globally upheld standards from the WHO. The WHO has provided a series of guidelines to assist policy makers in creating action plans that promote active and inclusive aging. Particularly, the Global Age-Friendly Cities Guide, and the Checklist of Essential Features of Age-Friendly Cities outlines features of age-friendly cities that touch upon the following eight pillars: outdoor spaces and buildings, transportation, housing, social participation, respect and social inclusion, civic participation and employment, communication and information, and community support and health services.

Cao, X., Mokhtarian, P. L., \& Handy, S. L. (2010). Neighborhood Design and the Accessibility of the Elderly: An Empirical Analysis in Northern California. International Journal of Sustainable Transportation, 4(6), 347-371.

This study analyzes the ability of neighbourhood design to preserve accessibility and independence for older adults through the design of neighbourhoods that focus less on the automobile, prioritizing walkability and transit options. The authors compared travel patterns and residential preferences of older and younger people, and determined that older adults "selfselect their residential neighborhoods to meet their travel preferences."

Kerr, J., Rosenberg, D., \& Frank, L. (2012). The Role of the Built Environment in Healthy Aging: Community Design, Physical Activity, and Health among Older Adults. Journal of Planning Literature, 27(1), 43-60. 
The authors provide evidence of the role that the built environment plays in extending the wellbeing and healthy living of older adults. The report discusses important features and design solutions that support older adults in creating more walkable communities that are safe and accessible. They stress the need for preserving and creating walkable communities as it reduces the risk of chronic disease and improves health overall. Moreover, in providing accessible communities independence is maintained.

\section{Mitra, R., Siva, H., \& Kehler, M. (2015). Walk-friendly suburbs for older adults? Exploring the enablers and barriers to walking in a large suburban municipality in Canada. Journal of Aging Studies, 35, 10-19.}

Walking is the most common and preferred form of physical activity among older adults. The authors outline the perceived risks and barriers associated with walking in a suburban context. They include traffic, the absence of traffic controls, safety, the quality of infrastructure, weather, and the need for destinations. The article identifies positive features that enhance seniors' mobility such as the presence of nature/parks, gradual curbs, benches or frequent resting areas, and familiarity and routine.

\section{Beard, J.R, Petitot, C. (2010). Ageing and Urbanization: Can Cities be Designed to Foster} Active Ageing? Public Health Reviews. 32.

This report provides a succinct review of the research and theories surrounding the built environment's effect on health later in life. It is a fairly technical report that offers a variety of specific design details and notes initiatives that support active ageing, thus providing a useful resource. 


\section{CHAPTER 3.5.2: DEMENTIA-FRIENDLY COMMUNITIES}

Brorsson, A., Ohman, A., Lundberg, S., \& Nygard, L. (2011). Accessibility in public space as perceived by people with Alzheimer's disease. Dementia, 10(4), 587-602.

Interviews were held with individuals who have been diagnosed with Alzheimer's disease to determine their experiences of accessibility in the public realm. As the disease progressed, the public space that the informants felt was comfortable gradually became smaller. Findings within this report can assist in the planning process as they provide an understanding of participant values in leading an active and independent lifestyle. The informants in this study highlighted that noise, crowding and the use of everyday technology influenced their perceived accessibility.

Mitchell, L., Burton, E., \& Raman, S. (2004). Dementia friendly cities: Designing intelligible neighbourhoods for life. Journal of Urban Design, 9(1), 89-101.

This report shares findings from research that reviewed the impact of neighbourhood design on older individuals with dementia in an urban context. The report discusses the concept of designing legible neighbourhoods, detailing the importance of wayfinding techniques. It also provides good practices regarding street layout, variation in form and land use, landmarks, and simple symbols.

Blackman, T., Mitchell, L., Burton, E., Jenks, M., Parsons, M., Raman, S., \& Williams, K. (2003). The Accessibility of Public Spaces for People with Dementia: A new priority for the 'open city'. Disability \& Society, 18(3), 357-371.

The authors discuss what they view as neglect on the part of environmental planning and design regarding dementia-friendly public spaces. Alongside a useful and detailed literature review, the article describes the opportunity for using virtual reality technology with individuals who experience dementia to test public spaces' friendliness and identify opportunities for developing an "open city". They discuss how dementia-friendly design choices benefit the community at large in improving navigation, social networks, and mobility. 
Sheehan, B., Burton, E., \& Mitchell, L. (2006). Outdoor wayfinding in dementia. Dementia, 5(2), 271-281.

This research reviews wayfinding techniques used by individuals with dementia. The results concluded that the built environment, particularly memorable landmarks, plays a large role in guiding individual travel decisions. Study participants struggled with planned or memorized routes, and were easily confused by conventional wayfinding aids (maps and signs).

\section{Mitchell, L., \& Burton, E. (2006). Neighbourhoods for life: Designing dementia- friendly outdoor environments. Quality in Ageing. 7(1), 26-33.}

Mitchell and Burton's study examines how individuals with dementia interact with outdoor environments and factors that can improve an individual's experience. Of particular significance, the research outlines the social constraints individuals with dementia face, as they are restricted to a limited walkable distance near their homes. Public spaces can be intimidating, distracting, and anxiety inducing. The report provides practical recommendations to enhance the outdoor experience at the neighborhood level. dementia-friendly environments are "familiar, legible, distinctive, accessible, comfortable and safe." 


\section{CHAPTER 3.6: VISUAL IMPAIRMENT}

There is a range of types of vision loss, including visual impairment, low vision, legal blindness and total blindness, and as a result there are a range of interventions to support individuals. Public bodies are well aware that conventional signage is insufficient and are legislated to use braille, however, making a city accessible for visual impairment goes beyond this. Techniques used for creating a visually accessible city include audible signals, standardized signage, contrasting colors, changes in texture, and orienting markers.

Literature on visual impairment is limited. Most studies are highly specific regarding the evaluation of certain design characteristics, such as detectable warnings systems (Jenness and Singer, 2008), and orientation cues (Scott et al., 2011), as well as general best practices (Causley, 2014). There is also a concern regarding the safety of Shared Spaces: streets which remove curb to create a larger public realm. Although popular in Europe, this design approach is being explored in some North American contexts (Parkin and Smithies, 2012; Havik et al., 2012). Studies conducted on Shared Spaces critique the unpredictable pedestrian experience it creates while offering some design solutions (Parkin and Smithies, 2012; Havik et al., 2012). Overall, literature surrounding visual impairment tends to represent a harmonious perspective that places a greater emphasis on design features that ensure safety. This emphasis on safety is not largely discussed in other categories of accessibility discussed in this paper.

Causley, D. (2014). Start with People. Plan Canada. 54(2): 20-25

Causley, a leading planner in Ontario on accessibility for visual impairment, has provided a practical guide to assist professionals in creating visually accessible cities. Although brief, the report offers best practices for street signage, sidewalk texture and audible signals that go beyond the traditional standards of implementation.

\section{Jenness, J., \& Singer, J. (2008). Visibility and Conspicuity of Detectable Warnings for Pedestrians with Visual Impairments. Transportation Research Record: Journal of the Transportation Research Board, 2073, 104-113.}

Jenness and Singer go into great detail regarding the concept of detectable warnings, which is the tactile change at the end of a curb or found on train platforms. The authors review the 
significance of color and texture, discussing the most appropriate detectable warning systems in various contexts.

Norgate, S. H. (2012). Accessibility of urban spaces for visually impaired pedestrians. Proceedings of the Institution of Civil Engineers -- Municipal Engineer, 165(4), 231-237.

Visual impairment is a significant contributor to the loss of independence among older people. Particularly, public spaces place a higher cognitive load on individuals, creating a higher safety risk. Norgate discusses the street experience of individuals with vision impairment. She notes the need for continuous non-visual information, distinct surfaces, and noticeable changes in curb heights.

Parkin, J., \& Smithies, N. (2012). Accounting for the Needs of Blind and Visually Impaired People in Public Realm Design. Journal of Urban Design, 17(1), 135-149.

An emerging area of streetscape design is the notion of Shared Space: curbless spaces for both pedestrians and cars. Although not widely incorporated in Ontario, some new developments are including Shared Space features. Shared Spaces create a safety hazard, as they are not predictable and legible spaces for those with visual impairments. To address concerns, the authors suggest including both audible and tactile features, as well as color, texture, and pattern contrasts.

Havik, E. M., Melis-Dankers, B. J., Steyvers, F. J., \& Kooijman, A. C. (2012). Accessibility of Shared Space for visually impaired persons: An inventory in the Netherlands. British Journal of Visual Impairment, 30(3), 132-148.

Returning to the concept of Shared Spaces, the removal of structures such as signs, traffic lights, and delineations is intended to result in more cautious road users. However, the result has been the creation of unpredictable and unstructured spaces that create a sense of unsafety for individuals with visual impairment. Particularly, the removal of traditional features like curbs negatively affect the training and habits of individuals, along with service animals, impeding navigation and orientation. The authors offer a variety of solutions to create safer, more predictable spaces. 
Scott, A., Barlow, J., Guth, D., Bentzen, B., Cunningham, C., and Long, R. (2011) Nonvisual Cues for Aligning to Cross Streets. Journal of Visual Impairment \& Blindness. 105(10): 648-661

An area of concern in urban design for individuals with visual impairment is the accuracy of orientation cues at street intersections. This study examines six cues for alignment and discusses the effectiveness of each. These alignment cues include slope only, bar tile perpendicular, bar tile parallel, detectable warning with a bar title, arrow, and returned curb. The most successful cues were those involving underfoot bars mounted perpendicular to the desired walking direction. 


\section{CHAPTER 3.7: MOBILITY}

The uneven experience of individuals with physical disabilities to their built environment is unfortunately common. It extends beyond the $\mathrm{OBC}$, which accounts for ramps and entrances, to include the experiences in public spaces such as sidewalks, parks, and transit systems. The difficulty in experiencing the built environment limits an individual's access to fully participate in their community. Social and environmental barriers often reinforce ableist perspectives; therefore, there is an opportunity to further address the physical mobility needs in planning.

The literature surrounding mobility often reviews the differentiated or exclusionary user experience, particularly emphasizing wheelchair user experience (Imrie and Kumar, 1998; Bromley, Matthews and Thomas, 2007; Audirac, 2008). Researchers echo each other in their call for policy development and the implementation of a policy framework (Ministry of Municipal Affairs and Housing, 2008; Matthews et al., 2003; Mojtahedi et al., 2008). Transit research is a particular area of focus, as it is often the largest source for human discomfort in mobility challenges (Audirac, 2008; Bromley, Matthews and Thomas, 2007). Some emerging trends that require further research in the literature include visitability for housing (Visitable Housing Canada, n.d.) and the exploration of the intersections between food, desserts, and disability (Mojtahedi et al., 2008). With regards to design approaches, there are some areas of contention between the use of barrier-free design (Ministry of Municipal Affairs and Housing, 2008) or the use of a more expansive approach found in universal design (Audirac, 2008; Bromley, Matthews and Thomas, 2007). Finally, unique to the discussion is Lid and Solvang's (2016) contribution on the person-environment interaction that takes a more psychological and social lens.

\section{Imrie, R., \& Kumar, M. (1998). Focusing on Disability and Access in the Built Environment. Disability \& Society, 13(3), 357-374.}

This article reviews the differentiated experience of individuals whose disability affects their mobility due to the built environment. These barriers restrict an individual's access to specific spaces. The article provides recommendations for the built environment that makes use of the opinions of individuals who participated in the study's focus group. 
Visitable Housing Canada. (n.d.). Guidelines for VisitAble Housing Measurements. Retrieved from http://visitablehousingcanada.com/wp-content/uploads/2016/03/CCDSVisitAbility-Measurements-Guidelines.pdf

This text provides design guidelines for visitability: the concept that homes be built in a manner that would accommodate an individual in a wheelchair to be able to access a space. Although this concept is limited to housing, the applications can be widely applied to various contexts.

Ministry of Municipal Affairs and Housing. (2008). Planning for Barrier-Free Municipalities. Retrieved from http://www.mah.gov.on.ca/Page1290.aspx

The Ministry of Municipal Affairs and Ministry of Housing provides a detailed and comprehensive outline for municipalities' approach to barrier-free design. It includes details regarding the design and implementation of a policy framework, in addition to summarizing municipal best practices.

Lid, I. M., \& Solvang, P. K. (2016). (Dis)ability and the experience of accessibility in the urban environment. ALTER - European Journal of Disability Research / Revue Européenne de Recherche sur le Handicap, 10(2), 181-194.

This study involved interviews with individuals with vision impairments and mobility restrictions regarding their experiences with the urban environment. The authors provide a nuanced perspective on the psychosocial dimensions that affect accessibility, further stressing the need for practitioners to see beyond the built form in the "person-environment interaction."

Mojtahedi, M. C., Boblick, P., Rimmer, J. H., Rowland, J. L., Jones, R. A., \& Braunschweig, C. L. (2008). Environmental Barriers to and Availability of Healthy Foods for People With Mobility Disabilities Living in Urban and Suburban Neighborhoods. Archives of Physical Medicine and Rehabilitation, 89(11), 2174-2179.

Food deserts have become an emerging field of research in planning and geography, adding a layer to the discussion is access to food for individuals. This study assessed the lack of access to healthy food options for individuals with limited mobility in low-income neighbourhoods. The findings stress the need for policies that address barriers to health and well-being for individuals 
with disabilities.

Bromley, R. D., Matthews, D. L., \& Thomas, C. J. (2007). City centre accessibility for wheelchair users: The consumer perspective and the planning implications. Cities, 24(3), 229-241.

Interviews with wheelchair users in an urban context highlighted the barriers participants faced within the built environment, public transit, and commercial experiences. The study findings are sorted into six areas of policy improvement: providing inclusive transit systems, progressing toward universal design, increasing consulting with individuals, increasing public awareness, recognizing the need for compromise, and incorporating good practices.

Matthews, H., Beale, L., Picton, P., \& Briggs, D. (2003). Modelling Access with GIS in Urban Systems (MAGUS): capturing the experiences of wheelchair users. Area, 35(1), 3445.

The authors use GIS to model the access of wheelchair users. The outcome of this project provides professionals with information to evaluate and develop processes that improve mobility. This approach can be replicated for municipalities to obtain their own data on route choices to improve their public systems.

Audirac, I. (2008). Accessing Transit as Universal Design. Journal of Planning Literature, 23(1), 4-16.

Audirac reviews universal design's ability to address exclusion amongst "mobility-disadvantaged populations"' access to transit in an American context. The text argues that universal design can redress social exclusion through its anticipatory nature and the desire to avoid future readaptations. Universal design has the potential to become a powerful tool in transit that allows for seamless integration of accessible features. 


\section{CHAPTER 4: RESULTS AND DISCUSSION}

Accessibility planning or consulting is a varied and robust profession. A total of twelve accessibility professionals who participated in this study were from both the private (9) and public sectors (3), practicing in a range of work that informed policy and design guidelines, while also addressing specific outcomes in the built environment, mobility, parks and public space, and public engagement. It is also important to note that four participants identified themselves as having a disability or multiple disabilities, explaining that this lived experience greatly shaped their work and priorities.

There was a clear distinction in the way participants approached their work, and two trends emerged. Some professionals identified themselves AODA experts, whose work placed a greater emphasis on meeting OBC standards and design guidelines as set out in the AODA. The second category of professionals were those who practiced planning from a more nuanced, broader perspective seeking to exceed the minimum standards set out in the OBC and AODA by incorporating a variety of contextually relevant best practices. As one professional described, the impetus is the AODA, it is imbedding the spirit of the AODA into services and practices. This imbedding and interpretation of the AODA was widely varied. 


\section{CHAPTER 4.1: DEFINING ACCESSIBILITY}

Some private and public sector professionals echoed each other in their attention to defining accessibility according to the AODA as well as stressing undifferentiated user experiences and barrier-free design. In contrast, one private sector interviewee was critical of the AODA's preface of accessibility "for all." The for all definition is not achievable as the participant explains, there's no absolutes in design outcomes. The private sector professionals were very aware that context and lived experience plays a significant role in shaping one's understanding.

Furthermore, the private sector participants overwhelmingly defined accessibility in reference to universal design, which is a popular trend emerging in the literature. As one participant described, universal accessibility means that not only the environment is accessible to everyone, but also having a policy framework in place, that monitors and regulates accessibility, not something that's optional. This is complementary to Audirac (2008) and Weisman (2000) who posit that universal design is a tool for addressing social exclusion through informed policy. With universal design it is important to be thoughtful of the process and practical design implementation that is mindful of the user.

In line with the literature, a minority of participants identified barrier-free design as being different from accessibility and inclusivity (Persson et al. 2014). Accessibility is more than a ramp, it accounts for the attitudes, training, and awareness of needs not simply physical space. The universal design perspective holds that buildings and environments be thought of thoroughly in a way that creates spaces that work for almost everyone and does not need adaptations or obvious features.

Almost all the interviewees explained that accessibility is about inclusion, although the level of inclusion was defined differently. Within this understanding of inclusion, there was general consensus that design efforts needed to be practical within context while still functional in their outcomes for the user groups they are prioritizing. 


\section{CHAPTER 4.2: SUCCESSFUL PROJECTS}

Technically successful projects are context specific, however, the following paraphrased statements grasp the essence of inclusivity that is captured when considering accessibility.

- Producing service, systems, space that account for and include everybody

- Using spaces without different levels of work required

- Service that all can use, and everyone can make choices and provide undifferentiated experiences

- Co-mingling customers

- Used as independently as possible

- Expected and not an afterthought

- Visitable for as many people as possible

- Accommodating within reasonable expectations

- Inclusive communication and engagement

- User-friendly and initiative without the typical symbology, making a whole building accessible

- Preventing new barriers

- Measures on the demographic to make sure individuals are being represented (in relation to engagement)

- Broadest elements for accessibility

- Measures improvements in the quality of life

Although the above statements are related to each other, they are still quite ambiguous. For example, how does one measure the inclusivity in a project or quality of life? The literature does not touch upon this, and the qualitative data suggests a need. There is an opportunity to develop an evaluative framework that can measure projects from a more social and psychological perspective to account for all user experiences as alluded to by Lid and Solvang (2016). 


\section{CHAPTER 4.3: HARMONIZED STANDARDS AND OUTCOMES}

The implementation of the AODA, design standards, and accessible outcomes are far from being consistent or harmonized. There was consensus among the interwees that the built form met minimum standards as set out in the OBC however, the treatment of the AODA as it relates to the built environment was varied according to private sector participants. Some public sector participants indicated that there was more harmony in Ontario and at the Federal level.

Despite the general consistency with the legislation, differences in outcomes emerge amongst municipalities who have different design guidelines or when there is a higher level of selfimposed design. One interviewee expressed that there is frustration in the design community in wanting a clear single document. This could be in the form of a document that would account for a higher and broader emphasis placed on inclusive design choices, not simply barrier-free considerations. The literature has also expressed the need for a harmonious design guideline that is reviewed regularly. 


\section{CHAPTER 4.4: BARRIERS}

Areas of contention amongst participants were the barriers they identified as impeding the prioritization and broadening of accessible outcomes that exceed minimum OBC and AODA built environment standards. 


\section{CHAPTER 4.4.1: FUNDING}

At the forefront, half of those interviewed discussed funding and the capital investment associated with accessibility as a significant barrier. It was discussed that retrofitting a building to become accessible is more expensive than incorporating accessible principles from the onset of the design; this is widely understood in the literature. What was not captured in the literature and mentioned by two public sector professionals were the barriers to obtaining funding for new technology and procurement, public sector has a unique challenge with procurement ... procurement favors the cheap, competitive bids; innovations are unable to compete. Particularly in the public sector, political leaders are responsible for the public spending, investment in innovation is met with hesitation, and risk ends up outweighing the rewards. Management of funds sometimes prevents public organizations from initiating long-term change.

With regards to the private sector, the development industry is hesitant to invest in accessible design principles as there is no enforcement requiring them to do so, as will be described in the follow section. 


\section{CHAPTER 4.4.2: MONITORING AND ENFORCEMENT}

From a legal perspective, there's nothing in the legislation that requires proactive modifications; if the building inspector approves it, then that's it. A quarter of participants were quite critical of the AODA and municipal policies in their inability to go beyond designing a ramp and a larger bathroom.

Most public and private sector bodies lack a formal audit system to continuously evaluate their projects--gaps tend to be identified through legislated Accessibility Advisory Committees or on a case by case complaint system, all of which can be time consuming and costly.

Returning to the opening statement, if the $\mathrm{OBC}$ is met upon inspection, then the role of the private and public sectors is accomplished. If the private sector is seeking to be proactive in their efforts then they may conduct a built environment audit and implement some design changes; however, these outcomes are varied.

The professionals identified the need for an independent body to monitor and enforce the AODA prior to filing a Human Rights complaint. They cited the United States (US) as having stronger enforcement efforts, however, there is little literature comparing the US and Canadian contexts. This is certainly an opportunity for further research and exploration. 


\section{CHAPTER 4.4.3: EDUCATION AND PERCEPTIONS}

Participants were nearly unanimous in their identification of education and public perception as the most significant barriers to achieving accessible outcomes. There is a need for a societal shift to occur, reducing the stigma associated with disability as well as the need to not separate accessible design from mainstream design.

A quarter of the participants were critical of the education planners, architects, and landscape architects received, which often overlooks barrier-free or accessible design, particularly as it relates to the professional accreditation processes. Due to the social construction of disability, planners have the tendency to not consider people of different abilities; this has resulted in exclusion of certain user groups.

In addition to professional education, public education was also thoroughly discussed as a means to raise the profile and awareness of disability and accessibility. There are many longestablished misconceptions: attitudinal barriers, stigma, lack of knowledge, and stigma for certain disabilities (intellectual disability) that are widely held by the public.

In essence, the biggest issue is ignorance. The attitudes of the public need to shift so as to motivate people and celebrate the various abilities people have rather than see disability as a constraint or see inclusive design as a barrier to creativity in design. This attitudinal shift would lead to a more inclusive society, but the steps to arrive at this point are fragmented and unexplored. 


\section{CHAPTER 5: NEXT STEPS AND CONCLUSION}

This project was intended to capture a snapshot of accessibility in planning and related fields, to understand how professionals are incorporating the AODA requirements while also going beyond minimum OBC standards. Unsurprisingly, within the interview process, a variety of opinions emerged that were reflected in the literature or that highlighted a research gap.

Going forward there is an opportunity to explore the processes of incentivizing or enforcing accessibility outcomes in Ontario, as this was an area of great critique for the professionals. There is potential to explore the US and Canadian contexts to identify the option of having stronger enforcement.

Other opportunities for future exploration also include the development of an evaluative tool that would allow for the harmonizing of outcomes across municipalities, although this could take a variety of shapes. Future work should emphasize social and psychological indicators to ensure that design choices and processes are allowing for undifferentiated experiences. In support of a clear evaluative framework, designers may benefit from a clear provincial or national design document that reconciles municipal differences.

Finally an attitudinal shift is necessary in forming an inclusive society. To achieve this, accreditation programs should be reviewed to ensure that professional education is capturing accessibility in the classroom.

The OBC provides a minimum responsibility for safety regarding the built form; it does not capture human dignity and a person's sense of well-being. There is a noteworthy difference between designing built form that is barrier-free and that which is accessible. This difference is not always understood in planning or related professions, nor is consideration for differentiated experiences prioritized in design efforts. Accessibility was never about providing a ramp but creating an atmosphere that is inclusive and undifferentiated. Planners in particular are advocates for the communities they work with; they have the opportunity to push the boundaries of design recommendations, public engagement, and policy construction to capture the nuances that truly impact an individual's life outcomes. Planners should not restrict themselves in their implementation of accessibility standards. Planners are responsible for disrupting patterns that 
have emerged in the profession that fail to support everyone equitably. Accessibility is a commitment to creating a community that is for everyone, always. 


\section{REFERENCES}

Audirac, I. (2008). Accessing Transit as Universal Design. Journal of Planning Literature, 23(1), 4-16.

Bauman, H. (2014). DeafSpace: A rich sensory world. Access by Design, 139, 17-25

Beard, J.R, Petitot, C. (2010). Ageing and Urbanization: Can Cities be Designed to Foster Active Ageing? Public Health Reviews. 32.

Beer, C. (2014). Charting a Path Forward: Report of the Independent Review of the Accessibility for Ontarians with Disabilities Act. Government of Ontario. Retrieved from https://www.ontario.ca/page/charting-path-forward-report-independent-review-accessibilityontarians-disabilities-act - section-3

Blackman, T., Mitchell, L., Burton, E., Jenks, M., Parsons, M., Raman, S., \& Williams, K. (2003). The Accessibility of Public Spaces for People with Dementia: A new priority for the 'open city'. Disability \& Society, 18(3), 357-371.

Bromley, R. D., Matthews, D. L., \& Thomas, C. J. (2007). City centre accessibility for wheelchair users: The consumer perspective and the planning implications. Cities, 24(3), 229-241.

Brorsson, A., Ohman, A., Lundberg, S., \& Nygard, L. (2011). Accessibility in public space as perceived by people with Alzheimer's disease. Dementia, 10(4), 587-602.

Causley, D. (2014). Start with People. Plan Canada. 54(2): 20-25

City of London. (2007). Facility Access Design Standards. Retrieved from https://www.Iondon.ca/city-hall/accessibility/Documents/FADS_2007_final.pdf

City of Mississauga. (2015). Facility Accessibility Design Standards. Retrieved from http://www.mississauga.ca/file/COM/City_Of_Mississauga_Facility_Accessibility_Design_Stand ards.pdf

City of New York (2001) The NYC Guidebook to Accessibility and Universal Design. Retrieved from: http://www.nyc.gov/html/ddc/downloads/pdf/udny/udny2.pdf

City of New York (2003) Universal Design New York . Retrieved from:

http://idea.ap.buffalo.edu/Publications/pdfs/udny1.pdf

City of Toronto. (2004). Accessibility Design Guidelines. Retrieved from https://www1.toronto.ca/static_files/equity_diversity_and_human_rights_office/pdf/accessibility_ design_guidelines.pdf

Cao, X., Mokhtarian, P. L., \& Handy, S. L. (2010). Neighborhood Design and the Accessibility of the Elderly: An Empirical Analysis in Northern California. International Journal of Sustainable Transportation, 4(6), 347-371.

Edwards, C., \& Harold, G. (2014). DeafSpace and the principles of universal design. Disability \& Rehabilitation, 36(16), 1350-1359. 
Gossett, A., Gossett, A., Mirza, M., Barnds, A. K., \& Feidt, D. (2009). Beyond Access: A Case Study on the Intersection Between Accessibility, Sustainability, and Universal Design. Disability and Rehabilitation: Assistive Technology, 4(6), 439-450.

Government of Ontario. (1990). Human Rights Code, R.S.O. 1990, c. H.19. Retrieved from https://www.ontario.ca/laws/statute/90h19

Government of Ontario (2001) Ontarians with Disabilities Act. Retrieved from https://www.ontario.ca/laws/statute/01032

Government of Ontario. (2005). Accessibility for Ontarians with Disabilities Act, 2005, S.O. 2005, c. 11. Retrieved from https://www.ontario.ca/laws/statute/05a11

Government of Ontario. (2015). Building Code. Retrieved from https://www.ontario.ca/laws/regulation/120332

Harold G. (2013) Reconsidering sound and the city: asserting the right to the Deaf-friendly city. Environment and Planning D: Society and Space. 31, 846-62.

Havik, E. M., Melis-Dankers, B. J., Steyvers, F. J., \& Kooijman, A. C. (2012). Accessibility of Shared Space for visually impaired persons: An inventory in the Netherlands. British Journal of Visual Impairment, 30(3), 132-148.

Imrie, R., \& Hall, P. (2001). Inclusive Design: Designing and Developing Accessible Environments. New York: Spon Press.

Imrie, R., \& Kumar, M. (1998). Focusing on Disability and Access in the Built Environment. Disability \& Society, 13(3), 357-374.

Jenness, J., \& Singer, J. (2008). Visibility and Conspicuity of Detectable Warnings for Pedestrians with Visual Impairments. Transportation Research Record: Journal of the Transportation Research Board, 2073, 104-113.

Kerr, J., Rosenberg, D., \& Frank, L. (2012). The Role of the Built Environment in Healthy Aging: Community Design, Physical Activity, and Health among Older Adults. Journal of Planning Literature, 27(1), 43-60.

Law, C. M., Yi, J. S., Choi, Y. S., \& Jacko, J. A. (2007). Unresolved Problems in Accessibility and Universal Design Guidelines. Ergonomics in Design: The Quarterly of Human Factors Applications, 15(3), 7-11.

Lid, I. M., \& Solvang, P. K. (2016). (Dis)ability and the experience of accessibility in the urban environment. ALTER - European Journal of Disability Research / Revue Européenne de Recherche sur le Handicap, 10(2), 181-194.

Matthews, H., Beale, L., Picton, P., \& Briggs, D. (2003). Modelling Access with GIS in Urban Systems (MAGUS): capturing the experiences of wheelchair users. Area, 35(1), 34-45.

Ministry of Municipal Affairs and Housing. (2008). Planning for Barrier-Free Municipalities. Retrieved from http://www.mah.gov.on.ca/Page1290.aspx 
Mitchell, L., \& Burton, E. (2006). Neighbourhoods for life: Designing dementia- friendly outdoor environments. Quality in Ageing. 7(1), 26-33.

Mitchell, L., Burton, E., \& Raman, S. (2004). Dementia friendly cities: Designing intelligible neighbourhoods for life. Journal of Urban Design, 9(1), 89-101.

Mitra, R., Siva, H., \& Kehler, M. (2015). Walk-friendly suburbs for older adults? Exploring the enablers and barriers to walking in a large suburban municipality in Canada. Journal of Aging Studies, 35, 10-19.

Mojtahedi, M. C., Boblick, P., Rimmer, J. H., Rowland, J. L., Jones, R. A., \& Braunschweig, C. L. (2008). Environmental Barriers to and Availability of Healthy Foods for People With Mobility Disabilities Living in Urban and Suburban Neighborhoods. Archives of Physical Medicine and Rehabilitation, 89(11), 2174-2179.

Norgate, S. H. (2012). Accessibility of urban spaces for visually impaired pedestrians.

Proceedings of the Institution of Civil Engineers -- Municipal Engineer, 165(4), 231-237.

Parkin, J., \& Smithies, N. (2012). Accounting for the Needs of Blind and Visually Impaired People in Public Realm Design. Journal of Urban Design, 17(1), 135-149.

Persson, H., Åhman, H., Yngling, A. A., \& Gulliksen, J. (2014). Universal Design, Inclusive Design, Accessible Design, Design for All: Different Concepts-One Goal? On the Concept of Accessibility-Historical, Methodological and Philosophical Aspects. Universal Access in the Information Society, 14(4), 505-526.

Regional Municipality of York. (2017). Accessibility Legislation. Retrieved from http://www.york.ca/wps/portal/yorkhome/yorkregion/yr/accessibility/accessibilitylegislation/

Salmi, P. (2009) Wayfinding Design: Hidden Barriers to Universal Access. Informed Design. 5(8): $1-6$

Scott, A., Barlow, J., Guth, D., Bentzen, B., Cunningham, C., and Long, R. (2011) Nonvisual Cues for Aligning to Cross Streets. Journal of Visual Impairment \& Blindness. 105(10): 648-661

Sheehan, B., Burton, E., \& Mitchell, L. (2006). Outdoor wayfinding in dementia. Dementia, 5(2), 271-281.

Solvang, P. K., \& Haualand, H. (2013). Accessibility and diversity: Deaf space in action. Scandinavian Journal of Disability Research, 16(1), 1-13.

Statistics Canada. (2012). Disability in Canada: Initial findings from the Canadian Survey on Disability. Retrieved from /react-text http://www.statcan.gc.ca/pub/89-654-x/89-654-x2013002eng.htm

Steinfeld, E., \& Maisel, J. (2012). Universal Design: Creating Inclusive Environments. Hoboken: John Wiley \& Sons, Inc.

United States Department of Justice Civil Rights Division. (1990). Americans with Disabilities Act of 1990. Retrieved from https://www.ada.gov/ 
United States Department of Justice and Civil Rights Division. (2010). ADA Standards for Accessible Design. Retrieved from https://www.ada.gov/regs2010/2010ADAStandards/2010ADAstandards.htm

Visitable Housing Canada. (n.d.). Guidelines for VisitAble Housing Measurements. Retrieved from http://visitablehousingcanada.com/wp-content/uploads/2016/03/CCDS-VisitAbilityMeasurements-Guidelines.pdf

Weisman, L. K. (2000). Creating the Universally Designed City: Prospects for the New Century. Architectural Theory Review, 5(2), 156-173.

World Health Organization (2002). Active aging: A policy framework. Retrieved from http://www.who.int/ageing/publications/active_ageing/en/

World Health Organization (2007). Global Age-Friendly Cities Guide. Retrieved from http://www.who.int/ageing/publications/Global_age_friendly_cities_Guide_English.pdf?ua=1

World Health Organization (2007). Checklist of Essential Features of Age-Friendly Cities. Retrieved from http://www.who.int/ageing/publications/Age_friendly_cities_checklist.pdf 


\section{GLOSSARY}

Ableist/Ableism

Accessible Design

Barrier-Free Design

Cooperative/Participatory Design Involves individuals who identify as having a disability in

d/Deaf Cultural Identity

Deafen

DeafSpace

Inclusive Design

Tactile

Universal Design

Visitability

Wayfinding the design process.

Discrimination or prejudice against people with disabilities; defining people based only on their disability.

Design focused on principles of extending standard design to persons with disabilities to maximize the number of potential individuals who can readily use a product, building or service (Persson et al., 2015).

Built form that is free from anything that prevents an individual from fully participating in all aspects of society.

Social beliefs and behaviors shared by those whose main form of communication is sign language.

Quieting a space.

Architectural design that caters to the needs of the hearing impaired.

Built form design that includes as many users as possible.

Perceptible by touch.

Design that produces environments to be usable by all people, to the greatest extent possible, without the need for adaptation or specialized design (The Centre for Universal Design, 1995; City of Toronto, 2004).

Measure of the ease of access to a space for people with disabilities.

Process of orienting oneself to navigate. 